\title{
BMJ Open Development of a toolkit to enhance care processes for people with a long- term neurological condition: a qualitative descriptive study
}

\author{
Ann Sezier, ${ }^{1}$ Suzie Mudge, ${ }^{1}$ Nicola Kayes, ${ }^{1}$ Paula Kersten, ${ }^{2}$ Deborah Payne, ${ }^{1}$ \\ Matire Harwood, ${ }^{3}$ Eden Potter, ${ }^{4}$ Greta Smith, ${ }^{1}$ Kathryn M McPherson ${ }^{5}$
}

To cite: Sezier A, Mudge S, Kayes N, et al. Development of a toolkit to enhance care processes for people with a long-term neurological condition: a qualitative descriptive study. BMJ Open 2018;8:e022038. doi:10.1136/ bmjopen-2018-022038

- Prepublication history for this paper is available online. To view these files, please visit the journal online (http://dx.doi. org/10.1136/bmjopen-2018022038).

Received 30 January 2018 Revised 13 April 2018 Accepted 16 May 2018

Check for updates

${ }^{1}$ Centre for Person Centred Research, Health \& Rehabilitation Research Institute, University of Technology, Auckland, New Zealand ${ }^{2}$ School of Health Sciences, University of Brighton, Brighton, UK

${ }^{3}$ Univeristy of Auckland, Auckland, New Zealand

${ }^{4}$ Design for Health and Wellbeing (DHW) Lab, Auckland District Health Board and Auckland University of Technology collaboration, Auckland, New

Zealand

${ }^{5}$ Health Research Council of New Zealand, Auckland, New Zealand

Correspondence to Ann Sezier; asezier@aut.ac.nz

\section{ABSTRACT}

Objective To (A) explore perspectives of people with a long-term neurological condition, and of their family, clinicians and other stakeholders on three key processes: two-way communication, self-management and coordination of long-term care; and (B) use these data to develop a 'Living Well Toolkit', a structural support aiming to enhance the quality of these care processes. Design This qualitative descriptive study drew on the principles of participatory research. Data from interviews and focus groups with participants $(n=25)$ recruited from five hospital, rehabilitation and community settings in New Zealand were analysed using conventional content analysis. Consultation with a knowledge-user group $(n=4)$ and an implementation champion group $(n=4)$ provided additional operational knowledge important to toolkit development and its integration into clinical practice. Results Four main, and one overarching, themes were constructed: (1) tailoring care:referring to getting to know the person and their individual circumstances; (2) involving others: representing the importance of negotiating the involvement of others in the person's longterm management process; (3) exchanging knowledge: referring to acknowledging patient expertise; and (4) enabling: highlighting the importance of empowering relationships and processes. The overarching theme was: assume nothing. These themes informed the development of a toolkit comprising of two parts: one to support the person with the long-term neurological condition, and one targeted at clinicians to guide interaction and support their engagement with patients.

Conclusion Perspectives of healthcare users, clinicians and other stakeholders were fundamental to the development of the Living Well Toolkit. The findings were used to frame toolkit specifications and highlighted potential operational issues that could prove key to its success. Further research to evaluate its use is now underway.

\section{INTRODUCTION}

The growing prevalence of long-term neurological conditions and the associated life-long physical, psychological and social support needs for individuals and their support

\section{Strengths and limitations of this study}

- This study originated from an implementation science perspective and demonstrated how a participatory-informed approach was successfully applied to inform the development of a toolkit to support people with a long-term neurological condition.

- Drawing on the experience-based knowledge from a range of stakeholders ensured that the proposed solution would be pragmatic, aligned with the needs of the healthcare user, and would increase the likelihood of uptake into clinical practice.

- This project was not originally conceptualised as design project and as a result did not consider design-oriented methodologies, which meant that although 'end user' experiences informed toolkit development, there was no direct user-designer interaction, which is an inherent limitation to this study.

- Data related to all three key processes informed the development of the toolkit; however, in doing so, some of the more nuanced interpretations relevant to each individual process may have been lost.

people is of worldwide concern, particularly given the significant societal burden and long-term healthcare utilisation. ${ }^{1-4}$ Preventing secondary impairments or premature deterioration, enhancing quality of life through promotion of health and well-being and enabling participation is in the forefront of healthcare reform. ${ }^{5-8}$ However, in many cases, care needs remain unmet and outcomes are poor, despite the investment and quality improvement efforts in acute, rehabilitation and community health services. ${ }^{1-4}$

Donabedian's seminal work, and many subsequent quality of care models, makes explicit that one needs to consider structures, processes and outcomes when critically reflecting on quality of care and that all are necessary and interact to produce good quality care. ${ }^{9} 10$ Despite this, it is common to look at outcomes without giving due 
consideration to the structures and processes that may make those outcomes possible. ${ }^{9-13}$ In doing so, we may inadvertently miss key aspects of structures or processes that may offer a useful target for intervention.

Research to date consistently highlights a number of aspects of care that need improving and that have the potential to contribute to better health outcomes. ${ }^{12-14}$ This appears to be particularly key in the following three core processes: (1) communication and information exchange between clinicians and individuals living with a long-term neurological condition and their family (from here on referred to as healthcare users); (2) harnessing healthcare users' skills and strengths to promote self-management; and (3) coordinating care across the lifespan. ${ }^{14-22}$

In this study we aimed to: (A) critically explore how these three processes could be improved, from the perspectives of clinicians and healthcare users, and (B) draw on those findings to develop and implement a structural support, a toolkit, to optimise those core processes in practice.

The importance of healthcare users' experience as a measure for quality in healthcare delivery and as a basis for improving patient engagement and health outcomes has become more widely recognised. ${ }^{23-25}$ As such, this project employed a participatory-informed approach premised on the notion that understanding and valuing the healthcare users' experiences as well as engaging key stakeholders in the development of a toolkit would be fundamental to its success. ${ }^{5} 6{ }^{23-29}$ Specific research questions for this current study were: (A) what are the tipping points people with long-term conditions experience in the context of person-centred communication; (B) what strengths and skills do people need to manage and live well with their condition; $(\mathrm{C})$ how can we better coordinate long-term care; and (D) in what way might a toolkit support the person and improve the experience of all three processes? The data generated by the qualitative phase of this project were then integrated into toolkit development.

\section{METHOD \\ Design}

This paper reports on the first phase of a larger implementation project. For this phase, qualitative description was chosen as the methodological framework being suitable for problem identification, applied research, and concept and instrument development. ${ }^{30} 31$

\section{Patient and public involvement}

Healthcare user experiences, captured in prior projects undertaken by the research team, informed the conceptualisation of the current project. Drawing on a participatory-informed approach, this project engaged with healthcare users and other key stakeholders, such as clinicians, service providers and patient advocates, to ensure the solution would be responsive to the healthcare users' needs at crucial points in their healthcare and enhance current clinical practice. ${ }^{24-29}$

Given the end goal of implementation into routine service delivery, we established a knowledge user group $(n=5)$ and identified implementation champions $(n=4)$ within each of our participating localities to work with us from the outset. The purpose of the knowledge user group was to provide information important to toolkit development as well as to provide insight into existing structures and processes pertinent to future implementation of the toolkit. Knowledge user group membership included representatives of a non-governmental organisation $(\mathrm{n}=1)$, patient advisory services $(\mathrm{n}=2)$ and service providers $(n=2)$. Implementation champions were clinicians seconded to the research from each of the participating localities, including a speech language therapist from a postacute inpatient brain injury service $(n=1)$, physiotherapists from one acute and one postacute hospital-based inpatient rehabilitation service $(n=2)$ and one physiotherapist from an outpatient neurorehabilitation clinic $(n=1)$. Their role was to help identify potential barriers and solutions for toolkit integration into clinical practice.

Research findings were shared with participants through newsletters and face-to-face meetings, depending on participant preferences. Many participants have also remained involved in subsequent phases of this work that include piloting, implementing and evaluating the toolkit in a range of clinical settings. Findings from these phases will be the subject of future publications.

\section{Participants and settings}

Participants were recruited from four localities across the Auckland region of New Zealand, including two primary healthcare services, one postacute intensive rehabilitation setting and one community-based neurorehabilitation clinic. Clinicians who were experienced in the management of people with long-term neurological conditions were informed of the study via a presentation given by a member of the research team. Interested clinicians could either contact the team directly or indirectly through their local implementation champion.

People with a long-term neurological condition were invited to take part in the study by the implementation champion or participating clinicians. They were eligible to take part if they were over 18 years of age, able to give informed consent and could take part in a focus group or individual interview conducted in English. Family were invited to take part if they were a significant other or the main carer for a person with a long-term neurological condition.

Purposive sampling was used to ensure diversity in condition, ethnicity, gender, age and time with condition for the healthcare user group. ${ }^{32}{ }^{33}$ Great care was taken to include Māori (indigenous people of New Zealand) participants to ensure their perspectives were represented, and findings of this study were relevant to them. ${ }^{345}$ Diversity 
was also sought within the clinician group based on their discipline and years of experience.

\section{Data collection}

Participants took part in a one-off, semistructured, individual face-to-face interview or focus group led by members of the research team. We held a Māori-specific focus group to explore any potentially cultural-specific issues in more depth. This focus group was led by a kaumātua (a Māori elder) who ensured principles of Kaupapa Māori (an indigenous-led approach to research in New Zealand) were upheld. ${ }^{35-37}$ Informed written consent was obtained from all participants.

Interviews and focus groups were held at locations most convenient or culturally appropriate for the participants and lasted on average between $60 \mathrm{~min}$ and $90 \mathrm{~min}$. The Māori focus group extended to approximately 3 hours allowing for processes customary to Kaupapa research such as mihi (traditional introductions), karakia (spiritual greetings) and manaaki (sharing of food) ${ }^{35-37}$ Interviews and focus groups were audio-recorded and transcribed verbatim by an independent transcriber.

Interviews and focus groups concentrated particularly on critical points in the healthcare journey, where participants had memorable positive or negative experiences relating to one or more of the three key concepts: communication, self-management and coordination of long-term care, and explored how best to operationalise support for each of these concepts (box 1). An iterative data collection process was followed, which allowed for earlier interviews to shape the direction of subsequent interviews.

\section{Data analysis}

Analysis started after the first interview and took place in parallel to data collection. Conventional content analysis, incorporating methods of constant comparison, was

\section{Box 1 Sample interview questions}

\section{Healthcare users}

If we think about sharing information either between healthcare providers, or between them and yourselves, what do you think would be a good way of doing this?

What are the resources or tools you use that help you to live well with your condition? What works well and what does not?

If we now think about how your needs may change over time, can you describe some of the ways you deal with changes, for example, as you grow older or when something new happens in your life?

\section{Clinicians}

Can you tell us about the things you currently do to facilitate two-way communication?

Can you tell us about how you currently support clients and their families to draw on their own personal resources to look after themselves and their condition?

What supports your approach in dealing with the changing needs of your clients and their families (eg, while in your service, transition to another service, when services cease)? used to identify data with similar meaning and construct themes of importance. ${ }^{38}{ }^{39}$ Regular analysis meetings with a core team of seven researchers ensured that a rigorous process to analysis was applied. ${ }^{33} 40$

In the first instance, two members of the research team, also involved in data collection and therefore familiar with the context in which the data were collected, independently engaged in a data familiarisation and line-byline coding process. Codes were allocated to all extracts relating to at least one of the three key processes under investigation. The entire dataset was initially coded three times before codes were finalised and defined by the core team. Code definitions were then mapped against related data extracts and grouped into meaningful clusters for each of the three key processes before being compared across the three processes. Looking across helped the team identify similarities and differences to construct the themes that could then underpin toolkit development.

A two-step approach was used to analyse the transcript of the Māori focus group. First, a Māori advisor ensured that Māori words used by participants were accurately translated and their meaning correctly interpreted. A Kaupapa Māori researcher then considered and expanded on the analysis that ensured that the deeper meaning of the conversation was preserved. ${ }^{36} 37$ Preliminary findings were shared with the knowledge user group to check for resonance with their experiences and insights and inform development of the toolkit.

\section{RESULTS \\ Study population}

Twenty-five participants $(\mathrm{n}=25)$ were recruited for this study: 14 healthcare users, including people with a longterm neurological condition $(\mathrm{n}=10)$ and significant others $(n=4)$, and 11 healthcare providers, including clinicians $(n=8)$ and support workers $(n=3)$.

The healthcare users' experience living with a longterm neurological condition ranged from a few weeks to more than 10 years. One participant sustained a neurological condition at birth and had a lifelong experience to share. Clinicians' experience of working with people with long-term neurological conditions ranged between 1 and 20 years and overall clinical experience between 2 and 30 years. Table 1 provides an overview of participant characteristics for each of the participant groups. Twelve participants took part in individual interviews, while 13 took part in focus group interviews. Focus groups included two separate clinician groups $(\mathrm{n}=4 \mathrm{each})$, one mixed healthcare user and family group $(n=3)$ and one Māori mixed healthcare user and support workers group $(n=4)$.

\section{Themes}

Four interconnecting main themes and one overarching theme were constructed (figure 1). The central organising concept of each theme is illustrated by quotations extracted from the data. Words omitted from the transcript extracts have been replaced by $[\ldots]$, and natural 
Table 1 Participant characteristics

\begin{tabular}{|c|c|c|c|c|c|}
\hline \multicolumn{2}{|c|}{ People with a long-term neurological } & \multicolumn{2}{|l|}{ Healthcare providers $(n=11)$} & \multicolumn{2}{|c|}{ Significant others $(n=4)$} \\
\hline Diagnosis & & Profession & & Role & \\
\hline Traumatic brain injury & 3 & Physiotherapist & 2 & Parent & 2 \\
\hline Stroke & 1 & Occupational therapist & 4 & Partner & 2 \\
\hline Spinal cord injury & 2 & Clinical psychologist & 1 & & \\
\hline Multiple sclerosis & 1 & Speech language therapist & 1 & & \\
\hline Cerebral palsy & 1 & Māori support worker & 3 & & \\
\hline Complex neurological condition & 2 & & & & \\
\hline \multicolumn{6}{|l|}{ Gender } \\
\hline Female & 5 & & 8 & & 4 \\
\hline Male & 5 & & 3 & & \\
\hline \multicolumn{6}{|l|}{ Ethnicity } \\
\hline NZ European & 7 & & 5 & & 2 \\
\hline NZ Māori & 1 & & 3 & & 1 \\
\hline Other European & & & 2 & & \\
\hline NZ Māori/European & 1 & & & & 1 \\
\hline Indian & & & 1 & & \\
\hline Fijian Indian & 1 & & & & \\
\hline
\end{tabular}

pauses in the conversation are denoted by (...). For anonymity, specific participant details in relation to data extracts have been omitted.

Theme one: tailoring care to the person and their needs

Tailored care referred to clinicians being cognisant of individual care needs, matching support to those needs, being mindful of the likelihood that these may change over time and being responsive to those changes. Getting to know healthcare users and their individual needs was considered crucial to tailoring care.

Healthcare users and clinicians universally agreed that personalisation is essential for satisfactory and effective healthcare delivery and that the person's 'uniqueness' should form the basis of all therapeutic interventions.

It's mainly I think, knowing what people's home lives are like. Because everybody is different (...) no one

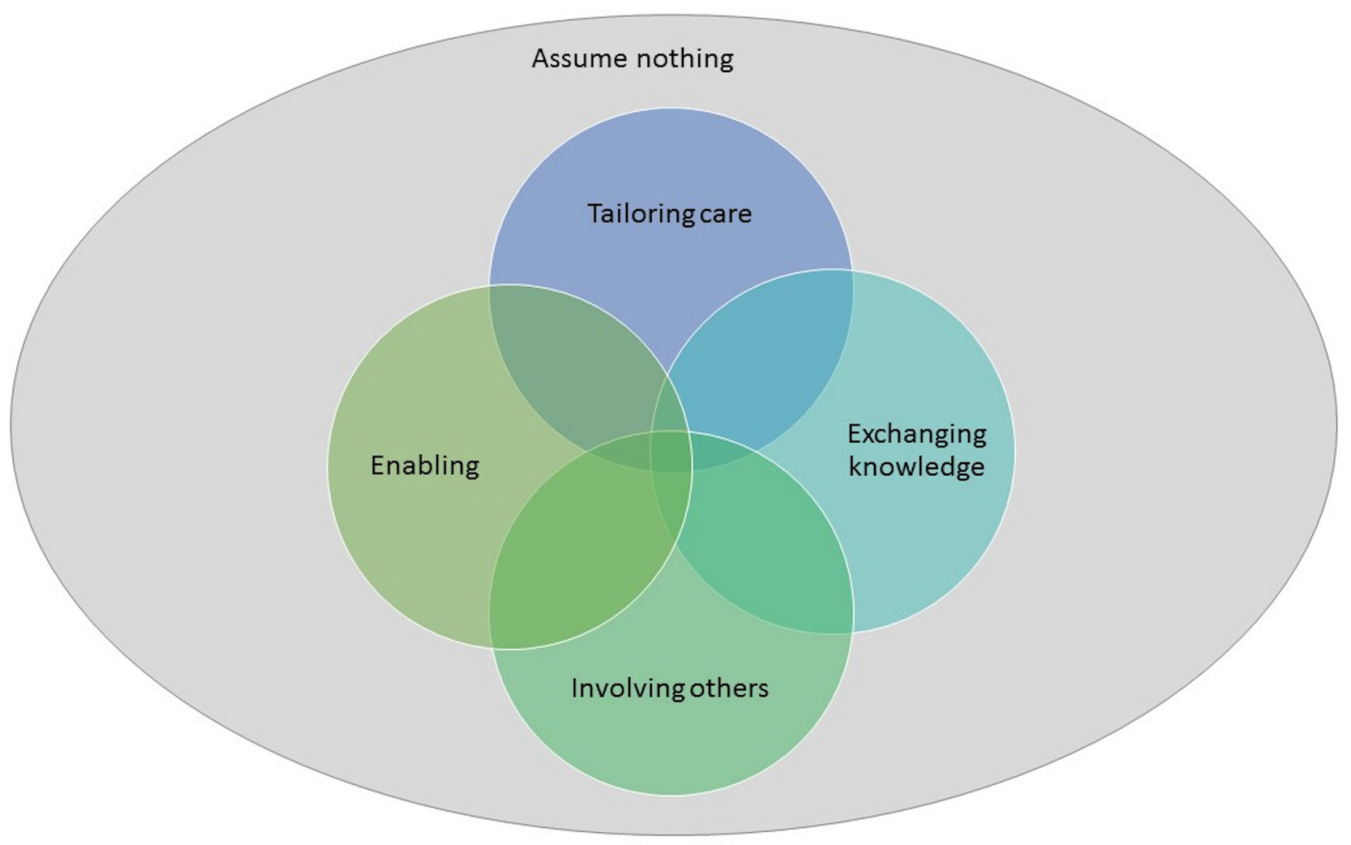

Figure 1 Schematic representation of themes. 
has got the same life so you have to make it, there is no one you can say that one shoe fits all. It has to have variation for personalised stuff. (Healthcare user 1)

The notion of tailored care was, however, not always translated into practice. While clinician participants professed to deliver tailored care, healthcare users often described their care as 'routine' and 'impractical', which made them feel care and support were meaningless.

In the context of communication, clinicians and healthcare users perceived tailored care to be related to 'readiness', a time where healthcare users are 'ready' to voice their needs and are 'ready' to process information. Readiness for receiving information and availability of information were however often poorly matched, with clinicians acknowledging that they frequently shared information and knowledge at times when individuals may be least receptive.

We do bombard people with so much information and these are people that find it very difficult to process and retain large amounts of information. (Clinician 1)

The analysis highlighted that identifying and being responsive to the healthcare users' individual care needs and readiness was a conscious process and a skill clinicians require.

I think clinicians do that very well on the whole. But I think we also underestimate what a skill that is. Because it is learnt over years and years of experience but I think you do change all the time about how you are interacting with people. (Clinician 2)

Despite the participating clinicians' perceptions that most health professionals possess this skill and tailor care well, healthcare users expressed frustration with the lack of opportunity given to discuss their needs, bringing into question whether and how clinicians identify the person's needs and readiness. When asked to elaborate on this issue one healthcare user responded:

I guess they come up with their list of things that they think need to be talked about or they think are issues.

(Healthcare user 2)

Tailoring care was also considered important for self-management and coordination of long-term care. One participant described his recovery posthead injury as having a 'rhythm'. Finding and respecting this rhythm was essential for him managing his condition. Failing to acknowledge or match care to his 'rhythm' was perceived as disruptive and unhelpful.

I guess the person who is doing the recovering invents their own schedule. But they just sort of expect (...) and you get into a rhythm and when that rhythm gets broken (...) it threw me off quite a bit. (Healthcare user 3)
Conversely, occasions where care was matched to the healthcare users' or family's needs were perceived as memorable and positive.

I think she did it perfectly to be honest. Yeah, I think she just gave me enough information to know that it was bad but not too much information to put me into more shock [I] have to say (...) she did an amazing job, I can't say, just fantastic. (Significant other)

\section{Theme two: involving others in the conversation}

Involving others pertains to establishing who is coming on the healthcare journey and considering with the healthcare user or support person, how to best coordinate their involvement.

Clinicians recognised that people function within a family unit and that in many cases there were people in that unit who would take on a role in providing lifelong support. Identifying who will take on this role and involving them in the continuum of care was identified as highly important and crucial to effective and satisfactory healthcare:

We try and involve the families as much as possibly because realistically we know that they are the ones that are going to have to take on board all the information and they are the ones that are going to have to support this (...) so the more knowledge and tools and strategies they have to be able to manage that person when they come home $[\ldots]$ the better because it's them really, they are the support people once they leave here. (Clinician 1)

Despite this recognition, involving support persons appeared to be transient or intermittent. For example, in the context of communication, clinicians identified that when clients were not in the position to state their preferences or communicate their needs, they would heavily rely on significant others as substitutes. However, their involvement seemed to become less pertinent once the client could better communicate or make their own decisions, only to regain importance at transitioning points. While in some cases this change in the level of involvement may have been appropriate and a reflection of the changing needs of the individual receiving care, support persons experienced this fragmented involvement as stressful and frustrating.

Clinicians acknowledged that support persons may have support needs of their own and that these may not necessarily be aligned with the client's needs or be directly related to the person in their care. However, they considered their duty of care lay foremost with their client and talked about feeling conflicted at times.

Actually he's our client and that's who we need to concentrate on, not, and we will support her (significant other) but not about some of her ongoing, her other issues which were to do with her really, not the 
situation necessarily. So trying to be supportive but not too involved. (Clinician 2)

Balancing loyalty for a client while attending to the needs of family was not a straightforward process and appeared difficult to operationalise. Knowing who to involve, how much and when appeared hard to gauge. For example, in the following extract, a healthcare user discusses how her daughter was asked to attend the discharge meeting.

Our daughter didn't cope at all. She said, 'Oh mother, you are just all about yourself.' And of course the meeting was about me. And she stormed out of the room and was very upset but she had never been involved before because her father and I were managing everything or otherwise I would manage on my own. (Healthcare user 4)

This example demonstrated that involving others without prior discussion or explicit consideration may not always be in the best interest of either party. It also brings to attention that family dynamics should be considered, that involving others does not necessarily mean involving next of kin and that the extent of involvement should be carefully considered. Where possible, healthcare users need to be consulted as to whom they would like to be involved, to what level and at what point, with the possibility of revision when circumstances change.

Our findings highlighted that involving others, similar to tailoring care, cannot be an automated process and requires explicit negotiation and needs to be managed in an ongoing way across the healthcare continuum.

\section{Theme three: exchanging knowledge}

Exchanging knowledge relates to acknowledging the healthcare user's expertise and matching knowledge transfer to their information processing capabilities and needs at that time.

Although clinicians recognised that healthcare users had lived experience and expert knowledge, they approached 'knowledge exchange' predominantly as a unidirectional, mostly educational process. Matching information to the healthcare user's level of understanding and taking into account levels of impairment were considered important in this somewhat didactic process.

Conversely, healthcare users referred to knowledge exchange as being able to have an open and honest dialogue where their knowledge was recognised and valued. In doing so, the person felt heard and listened to and perceived interactions as more meaningful.

I've found it really important for me to be able to speak with the other party on the same sort of level. So I myself am able to understand a lot of the muscles and the problems I've got like spasticity and stuff like that, which is harder for a lot of people to understand. So I can talk to specialists and ACC (Accident Compensation Corporation) and everybody on a level like that but I am really conscious that it has to sort of be adapted to the intellectual level that the person is thinking about their injury from. (Healthcare user 3)

Healthcare users also wanted clinicians to act as knowledge brokers, sharing information relevant to their condition or updating them on what was possible or available.

Yeah it really shows the importance of, so professionals working together, as well sort of sharing the knowledge and expertise and ideas and reviewing you know? The idea that things aren't stagnant so you need this conscious review. (Healthcare user 5)

Healthcare users were clear that knowledge exchange is a fluid process, open to fluctuations in direction and pace. There was one consistent message: knowledge exchange needs to be present from the beginning and clinicians need to be open and responsive to the knowledge that healthcare users bring. This was clearly demonstrated in the following extract where a participant talks about her experience of trying to share knowledge in preparation for the first home visit but where she felt her knowledge was not valued.

I was allowed home for one night. And I said, "It's taken me all week to plan this. I know I have [to] get home the Friday about lunch time, to go home and sleep for when the kids get home from school. You know go home and have a sleep, wake up.' And it took me all week to organise it. In that family meeting no one listened. Even my OT pipes up and says, 'What about the Saturday morning?' and I say, 'You are not listening.' By the time I had done the drive, get home I'm shattered, I'm knackered, I need sleep and my kids aren't going to understand that. So the most important thing is just to listen to the clients and they will tell you. No one seems to get that. (Healthcare user 6)

Clinicians perceived knowledge exchange to be particularly important at transition points (eg, when moving between services or at the time of discharge). However, healthcare users considered it to be important at all times, including after discharge. It was their view that information about what is available and how to access it should be available throughout the continuum of care. As a consequence, healthcare users valued clinicians who fostered knowledge exchange.

Well your first port of call often is your GP isn't it? So they need to be the ones also letting you know what's out there. What information is out there? You are entitled to Procare (primary healthcare organisation), free Procare appointments and all this stuff. I know these service providers seem to think they have a monopoly on the information. (Healthcare user 1)

Theme four: enabling the person to take control

This theme refers to enabling or empowering healthcare users to identify what strengths and skills they possess, 
need to build or consolidate to manage their condition and stay well over time.

Clinicians often discussed enablement in the context of knowledge transfer and referred to one-off events rather than skill building.

I think it's not always lack of knowledge because I think people pick up a lot of knowledge along the way but they don't always see how to translate that knowledge into the practical nitty gritty. (Clinician 5)

Ascertaining what skills and strengths healthcare users have to manage their condition, or to support a person with a long-term condition, did not appear to feature highly on the clinician's priority list, despite observing that a lack of skill or self-confidence was a barrier to living well. This could, in part, be due to clinician perceptions that confidence was a by-product of education and observation with very few clinicians considering that explicit skill building may be required as illustrated below.

I think having the client's family and people that are important to them actually attending rehab with them is really important (...) So they can actually see the approaches that are being taken by the rehab staff and model similar ones themselves (...) and just come along and see what they are doing and get involved and actually kind of being a bit more hands on I think helps because then they are not quite so concerned with, 'Well if I do it, am I doing it right?' or, 'Is there a certain way I should be doing these things?'. (Clinician 6)

At times, skills and confidence of healthcare users appeared to be assumed, causing unnecessary stress and anxiety for them.

Because they tested me, intelligence and retainability and stuff like that. All the stuff that was important to them, back there. And it doesn't really mean that it works here although it can. (Healthcare user 7)

The data also suggested that explicit attention to enabling did not appear to routinely begin until healthcare users approached a transition point, leaving little time for healthcare users to transfer skills and build much needed confidence.

So particularly at the end of a programme (...) So, we would then encourage their family to be quite proactive (...). So yeah, involve the family a lot, as much as possible really. (Clinician 2)

\section{Overarching theme: avoiding assumptions}

'Making assumptions' was a recurring thread in this study and forms the essence of this overarching theme. Clinicians and healthcare users recognised that making assumptions had an adverse effect on effective and satisfactory healthcare. Assumptions stood in the way of good two-way communication and in management and coordination of long-term care.
For example, in the context of communication and involving others, a significant other reflected on how assumptions hindered her husband's health and well-being:

It's a little bit like when [names husband] came off the acute ward into rehab he had been in a very noisy situation and he really felt like he just needed peace and quiet. He's a fairly reserved sort of person anyway. Not particularly gregarious. That's sort of what he asked for when he went onto the rehab just to be able to rest. So I finally got to go home and I came back and he had been moved from the single room to a room of 4 . Oh they felt that he was possibly depressed because he was so quiet. (Significant other 1)

In this case, assuming that her husband was depressed and moving him into a shared room was unsatisfactory for the healthcare user and his family.

The following extract is from a participant reflecting on how the assumption was made that she understood enough about her condition to make decisions that would have enduring impact.

The difficulty that I can see looking backwards was, the assumption that I had given thought to how my life could change $(\ldots)$ that assumptions are made that the patient has given any thought of the questions being asked of them, to give decisions on [...] and the patient won't have had any idea. Has mostly not even thought about it and yet they are being asked to give an answer. And a 'no' answer might exclude them from something they would like to be involved in and might not get another opportunity. (Healthcare user 4)

Making assumptions did affect the person living with the condition and affected their support people.

I think because of, they worked out that I was a nurse pretty quick and so nobody ever came round and checked our house like normal people would. Nobody did that. Nobody came around and said, 'Oh you are good' and, nobody actually came and said, 'Can we do anything to help you here?' Because they [just assumed]. He came home from his first weekend leave, nobody came around to check the environment because they trusted me, just because they knew me and they knew that I was there every day with him and but I would have really liked it if somebody did. (Significant other 2).

Clinicians talked about how healthcare users and family make assumptions too and expect to receive the tools and advice they need to live well without clearly communicating what support needs they have.

Because people [family] don't always tell us what they are doing, of course, and so then afterwards perhaps say, "You know if you had spoken to us before this is what we might have suggested, that might have made 


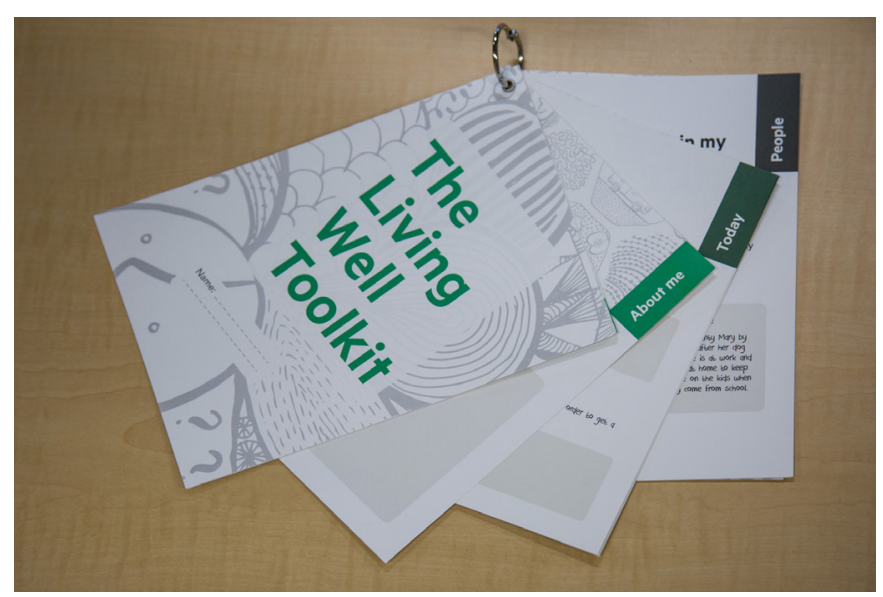

Figure 2 Healthcare user's tool.

the weekend more of a success rather than kind of picking up the pieces afterwards. (Clinician 6)

In this case, the assumption highlights a lack of structures and processes to support effective knowledge exchange. Clinicians here assumed that people have the skills to communicate important information, or even know what information might be pertinent to clinicians so that they can navigate and prevent negative experiences.

\section{Toolkit development}

The themes generated in this study provided novel insights into experiences of care to underpin a framework for toolkit design, informing its format and content and also helped determine how the toolkit could be operationalised in current healthcare systems. With the overarching theme in mind, the team focused on ensuring the toolkit served as a way of making two-way communication explicit and mitigate the risk of assumptions being made.

Our initial intention was to develop a toolkit for, and owned by, healthcare users to serve as a structural support to improve the three core processes. However, our engagement with healthcare users and practitioners during data collection and consultation with our knowledge user group highlighted that the toolkit would have limited success if implemented in isolation, without a companion guide to support clinicians to engage with healthcare users in a meaningful way. On this basis, a two-pronged approach to toolkit development ensued: (1) a paper-based tool owned by the healthcare users; and (2) a clinician's resource to support a way of working that was consistent with the philosophy and intention of the toolkit. This approach was considered crucial to successful uptake and implementation.

The toolkit's visual design, for both healthcare users' and clinicians' versions, was considered an important part of presenting the themes to encourage interaction. The research team collaborated with a mixed disciplinary design studio that takes a person-centred approach to the design of healthcare products, services and systems. In the design process, attention was paid particularly to graphical cueing, colour palettes, typography and use of abstract (rather than descriptive) illustrations. The design aimed to enhance ease of use and project a contemporary, reassuring look and feel.

The healthcare users' tool was a diary-sized booklet divided into three sections: 'All about me', 'Today' and 'People' (figure 2). 'All about me' aims to help the user to reflect on what matters most to them and their health and well-being, and communicate what they value when they receive healthcare. 'Today' is targeted at enabling the person to consider their needs with a specific healthcare encounter in mind to note what is relevant to them right now, and what they need from their clinician 'today'. The focus on 'today' was in response to the transient or changing nature of care and support needs. It also aims to empower the person to set the agenda for the session, rather than a session dominated by the clinician's agenda. Finally, 'Today' was intended to help healthcare users to reflect and communicate what they are currently doing for themselves, or for the person they support, to improve health and well-being. Additionally, help people with a long-term condition identify what their outstanding needs are and how they envisage support might be best tailored to them, and note anything else impacting their health and well-being at that time. The third section, 'People' encourages healthcare users to identify who plays a significant role in their lives, who is taking on a supporting role and may have support needs of their own. Importantly, it also acknowledged the interdependent nature of relationships and the role that they play themselves (eg, who and in what capacity others may rely on them).

The clinician's resource was developed to provide an intuitive, digestible and accessible prompt for practice as well as deeper layers of understanding to support toolkit uptake. The clinician's resource included two components: (1) a diary-sized prompt card featuring a central orienting question 'Who is this person and what do they need from me today?' on one side, and the acronym ADAPT standing for 'Assume nothing', 'Discuss', 'Acknowledge expertise', 'Promote partnering' and 'Tailor care' on the other side (figure 3); and (2) an interactive PDF.

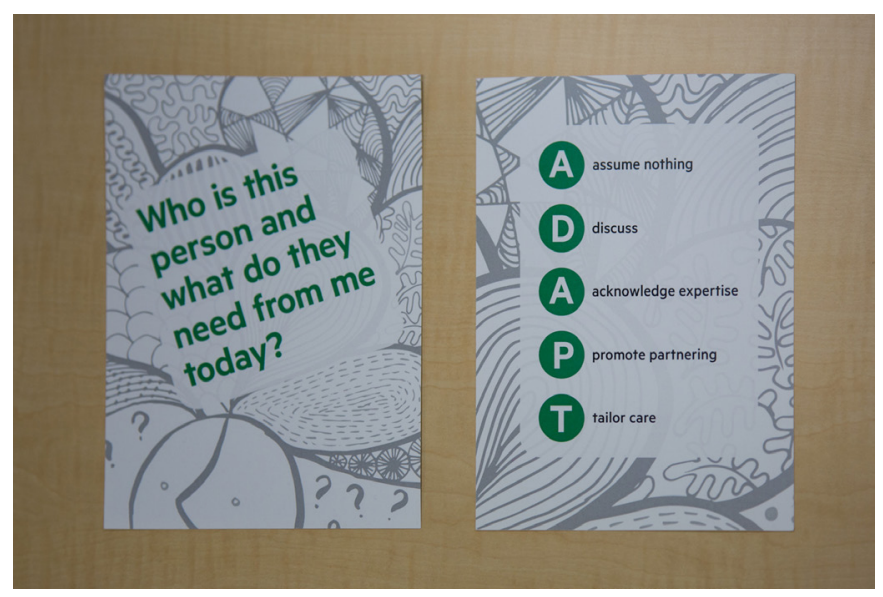

Figure 3 Clinician's prompt card. 


\begin{tabular}{|c|c|c|}
\hline $\begin{array}{l}\text { Toolkit } \\
\text { component }\end{array}$ & Specific components & Themes \\
\hline $\begin{array}{l}\text { All about } \\
\text { me }\end{array}$ & $\begin{array}{l}\text { 'What matters most to } \\
\text { me about my life, my } \\
\text { health and well-being' } \\
\text { and 'Things I value when } \\
\text { receiving healthcare'. }\end{array}$ & $\begin{array}{l}\text { Tailoring care, } \\
\text { exchanging } \\
\text { knowledge and } \\
\text { enabling. }\end{array}$ \\
\hline Today & $\begin{array}{l}\text { 'The most important issue } \\
\text { for me today', 'How I can } \\
\text { be best supported', 'What } \\
\text { I need to know', 'What } \\
\text { I am currently doing to } \\
\text { improve my health and } \\
\text { well-being' and anything } \\
\text { else impacting my health } \\
\text { and well-being today'. }\end{array}$ & $\begin{array}{l}\text { Tailoring care, } \\
\text { enabling and } \\
\text { exchanging } \\
\text { knowledge. }\end{array}$ \\
\hline People & $\begin{array}{l}\text { 'The key people in my } \\
\text { life and in what way they } \\
\text { support me and I support } \\
\text { them'. }\end{array}$ & $\begin{array}{l}\text { Involving others, } \\
\text { enabling and } \\
\text { tailoring care. }\end{array}$ \\
\hline ADAPT & $\begin{array}{l}\text { Assume nothing, Discuss, } \\
\text { Acknowledge expertise, } \\
\text { Promote partnering, and } \\
\text { Tailor care. }\end{array}$ & $\begin{array}{l}\text { Tailoring care, } \\
\text { exchanging } \\
\text { knowledge, } \\
\text { enabling and } \\
\text { Involving others. }\end{array}$ \\
\hline
\end{tabular}

The emphasis on avoiding assumptions in any of these domains.

The central guiding question aims to heighten sensitivity to the underpinning philosophy of the toolkit and serves as a starting point for all clinical encounters. The ADAPT acronym aims to provide a quick reference to key processes that help to operationalise this philosophy into practice.

The core team was referred back to the findings at each stage of toolkit development to ensure all toolkit and resource components were underpinned by all themes (table 2).

\section{DISCUSSION}

The Living Well Toolkit is a structural support designed to optimise key processes of person-centred care. ${ }^{9} 104142$ The main findings of this study were: (A) care needs to be personalised in order to be meaningful, which means that it has to be matched to the healthcare user's needs and values; (B) clinicians need to establish who healthcare users' support people are and how to best engage them in the care processes so that healthcare users live well; and $(\mathrm{C})$ healthcare users bring knowledge and expertise that may direct their care needs and avoid assumptions being made.

Congruent with other studies, our findings highlighted the importance of making therapeutic interactions more meaningful to healthcare users. ${ }^{9} 101942-45$ This appeared particularly crucial for helping healthcare users become more confident in their ability to manage their condition, take control over their health and well-being and claim a stake in how healthcare is delivered. ${ }^{41-47}$ Drawing on our findings, meaningful interactions appear more likely when clinicians (A) engage with healthcare users and family in an explicit but open and inviting way, and (B) give healthcare users the opportunity to direct the conversation. These essentials are consistent with a person-centred approach in healthcare delivery, which is characterised by respecting the person, taking into account their unique context and supporting active participation in the decision-making processes. ${ }^{15} 192148-57$ Our four main themes ('Tailoring care', 'Involving others', 'Exchanging knowledge' and 'Enabling') and the overarching theme of 'Avoiding assumptions' are consistent with conceptual understandings of person-centred practice. ${ }^{41} 4250$

In line with other studies, our findings exposed a discrepancy between the expectations of healthcare users and the clinicians' perceptions of meeting their clients' needs. ${ }^{49-52} 5758$ This may indicate that expectations are not explicitly discussed, or that there is no agreed plan, between clinician and healthcare users, on how expectations will be met. Furthermore, it raised the question of how deeply reflective practice is embedded in clinical practice, and if clinicians routinely check quality of care for each individual client, as part of reflective practice. The traditional model of practice, which supports the view of clinician as expert, may have contributed to this discrepancy. ${ }^{44} 5455$ Our findings support the notion that, to better meet the healthcare users' needs and expectations, a transformation of clinical practice may be required and that adopting a true person-centred approach is a conscious and challenging process requiring skill. ${ }^{45-58}$ The Living Well Toolkit is one way to support this transformation. Using the toolkit encourages clinicians to consciously engage with each healthcare user at a personal level and offers healthcare users an opportunity to identify and be explicit about their needs and expectations.

Our research provided deeper insight in the complexity of knowing who, when and how much to involve family or support persons in the caregiving process and highlighted that 'getting the balance right' was a problem for the healthcare user as well as clinicians. From our data, it was evident that family or carers have needs and expectations of their own that were often unmet. The existing literature emphasised that these needs and expectations need to be acknowledged and carefully managed to achieve improved long-term outcomes. ${ }^{59-62}$ The Living Well Toolkit provides an opportunity for healthcare users to identify who is involved or will be taking on a caregiving role and an opening to discuss what their involvement should be.

The discrepancy between the healthcare users' needs and clinicians' perceptions of meeting those needs continued to apply in the context of communication, where having a voice and being heard remained problematic for healthcare users. There was a clear disparity between what healthcare users want or need to know or share and the information or knowledge clinicians 
impart, a problem that also repeatedly surfaced in the existing literature. ${ }^{45} 465657$ Person-centred communication can positively influence health outcomes and satisfaction with care ${ }^{6364}$ Effective communication has been described as an essential but acquired skill not all clinicians master. ${ }^{656}$ The toolkit aims to ensure healthcare users have an opportunity to share their knowledge and indicate what information is needed to live well with their condition, while the principles that support ADAPT is intended to help clinicians build their communication skills and reflect on ways to make two-way communication more meaningful.

In the current healthcare climate, there is a growing interest in supporting healthcare users to 'live well' with a long-term condition supported by recent arguments for the change in rhetoric regarding the purpose of self-management, promoting a shift from 'managing the condition well' to 'managing well with the condition' ${ }^{5567-71}$ Supporting capability to manage the ongoing impact of injury or illness may be particularly important in the context of a health system where demand exceeds resources available. Very few would disagree with the notion that to 'live well' with a long-term condition, healthcare users need to have the capacity to manage life with a long-term condition and they need to be given the opportunity and be empowered to do so. Our fourth theme 'enabling the person to take control' highlights the complexity that resonates with other research in the field, in highlighting a tension between 'empowering' and 'controlling'. 464768 Our findings suggest that clinicians predominantly focus on empowerment at transition points. Enablement should arguably be considered and/ or included from the very first interaction between clinician and healthcare user, but it should also be recognised as a process that requires time and conscious engagement of healthcare users and clinicians. Therefore, we recommend that the toolkit is introduced at the beginning of each therapeutic relationship and serves as an anchor throughout the episode of care. The Living Well Toolkit aims to stimulate empowerment by helping clinicians become more mindful of their role in the enablement and empowerment processes and by opening up opportunities to get to know the person as a basis for tailored, meaningful care. ${ }^{41}{ }^{42}$ For healthcare users, the tool provides an opportunity to identify their existing skills, strengths and resources they can draw on to live well with their condition.

Taking a participatory-informed approach to toolkit development was one of the key strengths of this study. Engaging with a diverse group of key stakeholders as the starting point for the development of this intervention provided an opportunity to develop a solution that resonates with all parties as well as be applicable and sustainable in real-world environments, which is likely to augment its uptake and effectiveness. ${ }^{28}{ }^{29}$ While there was a risk that data from Māori participants could have been subsumed into all themes, we believe that this did not happen. Data from Māori participants were analysed both separately and in conjunction with the rest of the data to ensure that Māori perspectives were well represented within the themes.

Despite a delay in our engagement with the design team, we do consider our collaboration in the development of the toolkit to be a strength. Although the form and purpose of the Living Well Toolkit differed between the clinician's version (interactive PDF and prompt card) and the healthcare user's tool, it was important that the information design and graphic treatment were aligned across all material produced. This 'branded' the toolkit and reinforced our intention for it to be seen as a single resource by both user groups while enhancing perceptions of the resource as an attractive, purpose-designed system that aims to foster user engagement.

A limitation to this study was that despite our efforts to recruit for diversity, no Asian or Pasifika participants, who represent a growing percentage of the New Zealand population, took part in this research. As a result, we may have missed cultural-specific perspectives that could have informed or influenced aspects of The Living Well Toolkit. In addition, this study only sought the perspectives of people with a neurological condition. We anticipate that the Living Well Toolkit could potentially be of use to people with a range of long-term conditions, but this will need further investigation.

\section{CONCLUSION}

Engaging healthcare users in quality improvement initiatives is increasingly identified as important for improvement of health outcomes. This paper has discussed how adopting the principles of participatory research, drawing on experiences of healthcare users and providers, informed the development of a toolkit for people living with a long-term neurological condition. The Living Well Toolkit intends to provide structural support to improve two-way communication, self-management and coordination of care. The main findings highlighted how these components might be operationalised into practical strategies for both healthcare users and clinicians. Further research is needed to evaluate integration of the toolkit into practice before evidence about impact could be claimed. In the meantime, we propose that the toolkit is a theoretically sound, data-driven tool operationalising processes that are complex for clinicians and healthcare users alike.

Acknowledgements The authors gratefully acknowledge all participants in this study and all clinicians and managers from participating localities for supporting this project and their roles in recruitment. A special thanks to the Living Well Toolkit steering group members, who were also coapplicants in this study and served as scientific advisors, and Barbara Meier-Williams who was a research assistant and provided support with recruitment, data collection and data analysis.

Contributors KMM (PhD) was the principal investigator for this study, followed by $\mathrm{SM}(\mathrm{PhD})$. SM and NK (PhD) were the lead investigators in this project supported by a core group of health researchers: DP (PhD), PK (PhD), AEIS (MPhil) and GS. KMM, SM, NK, PK and DP are well-established researchers in the field of person-centred research and long-term neurological conditions. KMM, SM and AEIS conducted participant interviews and focus groups. KMM, SM, NK, GS, PK, DP 
and AEIS analysed all data. MH (PHD), an established Māori health researcher and coapplicant on this study, supported data analysis from Māori participants. EP (MA Art \& Des) and her team were responsible for toolkit design. AEIS is the first author and drafted this paper. All authors contributed to consecutive drafts and revisions. All authors have agreed to the final version of the paper.

Funding This work was supported by the New Zealand Health Research Council (HRC) grant number (13/285).

Competing interests KMM is now director of HRC (funder of this project); however, she was not appointed to this role at the time this study took place. Since her appointment, KMM has taken on an advisory role as part of the steering group only.

\section{Patient consent Not required.}

Ethics approval Approval for this study was granted by Health and Disability Ethics Committee HDEC (Ref: 13/NTA/209), and institutional ethics and subsequent approval was granted by Auckland University of Technology Ethics Committee (AUTEC 17/264) and research offices of all participating district health boards including Counties Manukau District Healthboard (Ref: 1671) and Waitemata District Healthboard (Ref: RM0980712877).

Provenance and peer review Not commissioned; externally peer reviewed.

Data sharing statement № additional data are available.

Open access This is an open access article distributed in accordance with the Creative Commons Attribution Non Commercial (CC BY-NC 4.0) license, which permits others to distribute, remix, adapt, build upon this work non-commercially, and license their derivative works on different terms, provided the original work is properly cited and the use is non-commercial. See: http://creativecommons.org/ licenses/by-nc/4.0/

(C) Article author(s) (or their employer(s) unless otherwise stated in the text of the article) 2018. All rights reserved. No commercial use is permitted unless otherwise expressly granted.

\section{REFERENCES}

1. Jackson D, McCrone P, Mosweu I, et al. Service use and costs for people with long-term neurological conditions in the first year following discharge from in-patient neuro-rehabilitation: a longitudinal cohort study. PLoS One 2014:9:e113056.

2. Lopez AD, Mathers CD, Ezzati M, et al. Global burden of disease and risk factors. New York, Ny: The World Bank and Oxford University Press, 2006.

3. Siegert RJ, Jackson DM, Playford ED, et al. A longitudinal, multicentre, cohort study of community rehabilitation service delivery in long-term neurological conditions. BMJ Open 2014;4:e004231.

4. World health Organization Neurological disorders. Public health challenges. WHO Press [internet]. 2006:P232 http://www.who.int/ mental_health/neurology/neurological_disorders_report_web.pdf.

5. Armitage GD, Suter E, Oelke ND, et al. Health systems integration: state of the evidence. Int J Integr Care 2009;9:e82.

6. Kodner DL. All together now: a conceptual exploration of integrated care. Healthc Q 2009;13 Spec No:6-15.

7. Suter E, Oelke ND, Adair CE, et al. Ten key principles for successful health systems integration. Healthc Q 2009;13 Spec No:16-23.

8. Valentijn PP, Schepman SM, Opheij W, et al. Understanding integrated care: a comprehensive conceptual framework based on the integrative functions of primary care. Int J Integr Care 2013;13.

9. Donabedian A. Evaluating the Quality of Medical Care. Milbank Mem Fund Q 1966;44:166-206.

10. Donabedian A. The quality of care. How can it be assessed? JAMA 1988;260:1743-8.

11. Øvretveit J. The economics of quality--a practical approach. Int $J$ Health Care Qual Assur Inc Leadersh Health Serv 2000;13:200-7.

12. Porter ME, Lee TH. The strategy that will fix health care. Harvard business review. 2013 https://hbr.org/2013/10/the-strategy-that-willfix-health-care (Retrieved Nov 2017).

13. Adams RJ. Improving health outcomes with better patient understanding and education. Risk Manag Healthc Policy 2010;3:61-72.

14. Street RL, Makoul G, Arora NK, et al. How does communication heal? Pathways linking clinician-patient communication to health outcomes. Patient Educ Couns 2009;74:295-301.

15. Bright FA, Boland P, Rutherford SJ, et al. Implementing a clientcentred approach in rehabilitation: an autoethnography. Disabil Rehabil 2012;34:997-1004.
16. Kayes NM, Mudge S, Cull A, et al. The Living well for disabled people project - Final report 2011. Research commissioned by the Ministry of Health. Auckland: AUT University.

17. Kayes NM, McPherson KM. Human technologies in rehabilitation: 'Who' and 'How' we are with our clients. Disabil Rehabil 2012;34:1907-11.

18. McLaughlin D, Hasson F, Kernohan WG, et al. Living and coping with Parkinson's disease: perceptions of informal carers. Palliat Med 2011;25:177-82

19. McPherson KM, Kayes N, Bishop M, et al. Making rehabilitation engaging. Brain Inj 2012;26:495.

20. Ranmuthugala G, Nepal B, Brown L, et al. Impact of home based long term care on informal carers. Aust Fam Physician 2009;38:618-20.

21. Rosewilliam S, Roskell CA, Pandyan AD. A systematic review and synthesis of the quantitative and qualitative evidence behind patient-centred goal setting in stroke rehabilitation. Clin Rehabil 2011;25:501-14.

22. Simon C, Kumar S, Kendrick T. Cohort study of informal carers of first-time stroke survivors. Soc Sci Med 2009;69:404-10.

23. Donetto S, Pierri P, Tsianakas V, et al. Experience-based co-design and healthcare improvement: realizing participatory design in the public sector. The Design Journal 2015;18:227-48.

24. Paulovich B. Design to Improve the Health Education Experience: using participatory design methods in hospitals with clinicians and patients. Visible Lang 2015;49:144-59.

25. Robert G. Participatory action research: using experience based co-design to improve quality of healthcare services. University Press scholarship online 2016.

26. Schmittdiel JA, Grumbach K, Selby JV. System based participatory research in healthcare. Ann Fam Med 2010;89:256-9.

27. Bergold J, Thom S. Participatory Research Methods: A Methodological Approach in Motion. Forum Qual Soc Res 2012;13.

28. Yardley L, Ainsworth B, Arden-Close E, et al. The person-based approach to enhancing the acceptability and feasibility of interventions. Pilot Feasibility Stud 2015;1:37.

29. Yardley L, Morrison L, Bradbury K, et al. The person-Based approach to Intervention Development: Application to Digital Health-Related Behaviour Change Interventions. J Med Internet Res 2015;17(1.

30. Neergaard MA, Olesen F, Andersen RS, et al. Qualitative description - the poor cousin of health research? BMC Med Res Methodol 2009;9:52.

31. Sandelowski M. What's in a name? Qualitative description revisited. Res Nurs Health 2009;33:77-84.

32. Patton MQ. Qualitative Evaluation of Research Methods. 3rd edn. London, UK: Sage, 2002.

33. Barbour RS. Checklists for improving rigour in qualitative research: a case of the tail wagging the dog? BMJ 2001;322:1115-7.

34. Ormond A, Cram F, Carter L. Researching our Relations: Reflections on Ethics and Marginalisation. AlterNative: An International Journal of Indigenous Peoples 2006;2:174-93.

35. Reid P, Paine SJ, Curtis E, et al. Achieving health equity in Aotearoa: strengthening responsiveness to Māori in health research. $N Z$ Med J 2017;130:96-103.

36. Health Research Council. Guidelines for researchers on Health Research involving Maori. Auckland: Health Research council of New Zealand, 1998.

37. Smith LT, Methodologies D. Research and indigenous peoples. Dunedin, NZ: University of Otago Press, 1999.

38. Hsieh HF, Shannon SE. Three approaches to qualitative content analysis. Qual Health Res 2005;15:1277-88.

39. Charmaz K. Constructing grounded theory: a practical guide through qualitative analysis. London: UK, Sage Publications, 2006.

40. Mays N, Pope C. Rigour and qualitative research. BMJ 1995;311:109-12.

41. McCance TV. Caring in nursing practice: the development of a conceptual framework. Res Theory Nurs Pract 2003;17:101-16.

42. McCormack B, Karlsson B, Dewing J, et al. Exploring personcentredness: a qualitative meta-synthesis of four studies. Scand $J$ Caring Sci 2010;24:620-34

43. Kennedy A, Rogers A, Bower P. Support for self care for patients with chronic disease. BMJ 2007:335:968-70.

44. Mudge S, Kayes N, McPherson K. Who is in control? Clinicians view on their role in self-management approaches: a qualitative metasynthesis. BMJ Open 2015;5:e007413.

45. McPherson KM, Gibson BE, Leplege A, eds. Whose behavior matters? Rethinking practitioner behavior and its influence on rehabilitation outcomes. Rethinking rehabilitation theory and practice. Boca Raton,FL: CRC Press, Taylor \& Francis, 2015:249-71. 
46. Mudge S, Rosie J, Stott S, et al. Ageing with cerebral palsy; what are the health experiences of adults with cerebral palsy? A qualitative study. BMJ Open 2016;6:e012551.

47. Snow R, Humphrey C, Sandall J. What happens when patients know more than their doctors? Experiences of health interactions after diabetes patient education: a qualitative patient-led study. BMJ Open 2013;3:e003583.

48. Cott CA. Client-centred rehabilitation: client perspectives. Disabil Rehabil 2004;26:1411-22.

49. Fadyl JK, McPherson KM, Kayes NM. Perspectives on quality of care for people who experience disability. BMJ Qual Saf 2011;20:87-95

50. Leplege A, Gzil F, Cammelli M, et al. Person-centredness: conceptual and historical perspectives. Disabil Rehabil 2007;29:1555-65

51. Peoples H, Satink T, Steultjens E. Stroke survivors' experiences of rehabilitation: a systematic review of qualitative studies. Scand J Occup Ther 2011;18:163-71.

52. Mudge S, Stretton C, Kayes N. Are physiotherapists comfortable with person-centred practice? An autoethnographic insight. Disabil Rehabil 2014;36:457-63.

53. Moore L, Britten N, Lydahl D, et al. Barriers and facilitators to the implementation of person-centred care in different healthcare contexts. Scand J Caring Sci 2017;31:662-73.

54. Norris M, Kilbride C. From dictatorship to a reluctant democracy: stroke therapists talking about self-management. Disabil Rehabil 2014;36:32-8.

55. Jones F, Riazi A. Self-efficacy and self-management after stroke: a systematic review. Disabil Rehabil 2011;33:797-810.

56. Hawkes $N$. Seeing things from the patients' view: what will it take? BMJ 2015;350:g7757.

57. MacLeod R, McPherson KM. Care and compassion: part of personcentred rehabilitation, inappropriate response or a forgotten art? Disabil Rehabil 2007;29:1589-95.

58. McPherson KM, Siegert RJ. Person-centred rehabilitation: rhetoric or reality? Disabil Rehabil 2007;29:1551-4.

59. Kreutzer JS, Marwitz JH, Kepler K. Traumatic brain injury: family response and outcome. Arch Phys Med Rehabil 1992;73:771-8.
60. Kreutzer JS, Gervasio AH, Camplair PS. Primary caregivers' psychological status and family functioning after traumatic brain injury. Brain Inj 1994;8:197-210.

61. McLaughlin AM, Carey JL. The adversarial alliance: developing therapeutic relationships between families and the team in brain injury rehabilitation. Brain Inj 1993;7:45-51.

62. Ponsford J, Olver J, Ponsford M, et al. Long-term adjustment of families following traumatic brain injury where comprehensive rehabilitation has been provided. Brain Inj 2003;17:453-68.

63. Oliveira VC, Refshauge KM, Ferreira ML, et al. Communication that values patient autonomy is associated with satisfaction with care: a systematic review. J Physiother 2012;58:215-29.

64. Pinto RZ, Ferreira ML, Oliveira VC, et al. Patient-centred communication is associated with positive therapeutic alliance: a systematic review. J Physiother 2012;58:77-87.

65. Mauksch LB, Dugdale DC, Dodson S, et al. Relationship, communication, and efficiency in the medical encounter: creating a clinical model from a literature review. Arch Intern Med 2008;168:1387-95

66. Street RL, Gordon H, Haidet P. Physicians' communication and perceptions of patients: is it how they look, how they talk, or is it just the doctor? Soc Sci Med 2007;65:586-98.

67. Wilson PM, Kendall S, Brooks F. The Expert Patients Programme: a paradox of patient empowerment and medical dominance. Health Soc Care Community 2007;15:426-38.

68. Asimakopoulou K, Newton P, Sinclair AJ, et al. Health care professionals' understanding and day-to-day practice of patient empowerment in diabetes; time to pause for thought? Diabetes Res Clin Pract 2012;95:224-9.

69. Entwistle V, Cribb A. Enabling People to Live Well: Fresh Thinking About Collaborative Approaches to Care for People with Long Term Conditions. London: The Health Foundation, 2013.

70. Morgan HM, Entwistle VA, Cribb A, et al. We need to talk about purpose: a critical interpretive synthesis of health and social care professionals' approaches to self-management support for people with long-term conditions. Health Expect 2017;20:243-59.

71. Eaton S, Roberts S, Turner B. Delivering person centred care in long term conditions. BMJ 2015;350:h181. 